\title{
APPLICATION OF A SUSTAINABILITY ASSESSMENT FRAMEWORK FOR FLOOD MITIGATION PROJECTS: A CASE STUDY ON A FLOOD LEVEE PROJECT IN AUSTRALIA
}

\author{
MOHAMMAD AMINUR RAHMAN SHAH, ANISUR RAHMAN \& SANAUL HUQ CHOWDHURY \\ School of Engineering, Griffith University, Australia
}

\begin{abstract}
Sustainable development of floodplains is closely linked to the sustainable flood mitigation measures. Various sustainability assessment (SA) methods to evaluate the influence of policies, plans or projects towards sustainable development have been emerging in recent years; however, most of them are national or regional policies and programs. Very few research studies have been carried out for sustainability assessment of flood mitigation projects. This paper presents the concept of a proposed sustainability assessment framework for flood mitigation projects and its application to a recently implemented flood levee project in Australia. This research has employed a review of the life cycle of flood mitigation projects, sustainability assessment methodologies, consultations with experts, and a case study of flood mitigation projects. In line with the project life cycle, the proposed sustainability assessment framework is developed incorporating five stages: a) contextualizing the project, b) SA during planning and implementation, c) SA during flood event, d) SA at periodic intervals, and e) SA at modification phase or changing to a new project. The application of the SA framework to the first two stages of a flood levee project demonstrates how the best suitable alternative levee option can be chosen in the planning stage by determining a sustainability index (SI) of the possible alternatives using a set of sustainability indicators. The study also shows achievement towards sustainability of the finally implemented project which can be compared with the originally planned project using the SA framework. The application of the SA framework suggests the potential for better decision making for individual flood mitigation projects, taking into account the sustainable outcome of the project as well as linking this to regional sustainable development.

Keywords: flood mitigation projects, sustainability assessment, decision support framework, project life cycle, multi-criteria analysis.
\end{abstract}

\section{INTRODUCTION}

Flood mitigation projects like levees and dams play a key role in flood risk reduction and sustainable development in floodplains. These projects are usually undertaken as a response to severe floods without considering long-term sustainability issues in their planning and design, due to a shortage of time and funds, which often leads to the project failing to achieve expected flood risk reduction, further socio-economic and environmental degradation, and generating new risks due to unanticipated development [1], [2]. The existing planning process of flood mitigation projects usually emphasizes the mitigation structures only. The design, implementation, and monitoring of such mitigation structures are primarily based on how much flood prevention the structures can provide, with some focus on environmental and socio-economic impacts in the design and implementation stage only. After implementation, regular monitoring of the mitigation structures is usually continued over the years, especially during floods, without monitoring the environmental and socio-economic changes in the project area caused by the project. The current project planning approach does not adequately emphasize the long-term environmental, social, and economic issues related to effective project performance and sustainable development in the region [3]-[5]. 
Incorporating sustainability issues in the planning and implementation of development programs has been of interest to researchers and planners over the years. Sustainability assessment (SA) of national or regional policies and programs and individual projects is considered a suitable way of incorporating sustainability issues into policies, programs or projects [6], [7]. Several sustainability assessment tools have been developed to measure the contribution of such development policies and programs towards the achievement of sustainable development. For instance, at the national level there exists the Genuine Progress Index (GPI) and the Dashboard of Sustainability [7], and for regional policy or program assessment several other options: the sustainability test [8], Telos sustainability assessment tools [9], sustainability appraisal guidance for regional and local authorities [10], decision-support methodology for assessing the sustainability of natural risk management strategies [11] and the sustainability assessment framework for regional-scale integrated coastal zone management (ICZM) [12]. Notably, none of the national and regional level sustainability assessment tools have been linked to individual projects implemented at the local level. As the sustainable development of a country or region can be achieved through implementing individual projects sustainable at the local level, there should be an integrated sustainability assessment approach that can link the sustainable development goals from local to national levels [5]. Recently, a few scientists have proposed a sustainability assessment approach for individual projects such as the integrated sustainability assessment (ISA) model for appraising development proposals by local government [13], and the analytical decision model for sustainability appraisal in infrastructure projects (SUSAIP) [14].

In particular, for flood mitigation projects, which require integrated assessment considering present and future environmental, social, and economic issues, there were very limited initiatives taken to develop sustainability assessment tools. Kumar et al. [15] have developed a sustainability assessment process for an urban river corridor re-development project in Sheffield, in the UK, using a Bayesian belief network (BN) based integrated model for determining the best sustainable scenario for the project. DEFRA [16] has recently proposed sustainability appraisal guidance for evaluating flood and coastal erosion management related policies, plans and schemes in the UK. This approach has utilized sustainability ranking and other performance indicators like environmental impact, operation and maintenance, and health and safety to appraise the alternative options for flood mitigation projects, but in the planning stage only [17]. The approach was not developed further for sustainability assessment in the post-implementation stages of the projects.

Overall, it appears that recently developed sustainability assessment methods for individual projects were primarily focused on determining the best alternative option only; however, there is no mechanism to validate whether the selected best alternative option will actually be sustainable in the future. Therefore, sustainability assessment should be an integral part of the whole life cycle of the project from planning to implementation, operation and maintenance, monitoring, and decommissioning/modification stages [16]. It is necessary to have a systematic approach for evaluating the potential of sustained flood risk reduction by flood mitigation projects as well as for determining the project's influence on the sustainable development of the floodplain.

In view of the above contexts, the authors have developed a decision support framework for sustainability assessment of flood mitigation projects based on the life cycle of the project [18]. The purpose of this paper is to present a general concept of the proposed sustainability assessment framework and the results of the application of the framework in a 
case study flood mitigation levee project in Queensland, Australia. The paper also discusses the research limitations, further scope for research, and improvement of the framework.

\section{THE SA FRAMEWORK FOR FLOOD MITIGATION PROJECTS}

Flood mitigation projects like levees and dams are thought to have an adverse impact on the environment and communities in the floodplains in spite of providing flood mitigation to properties, and agricultural and commercial sectors. While some of the environmental and socio-economic issues are considered in the planning of flood mitigation projects [13], [19], [20], further monitoring and evaluation of those impacts are not continued for the long term to evaluate or even perceive the real impacts or benefits caused by such projects. It is imperative to assess the impacts of flood mitigation projects throughout the whole project lifecycle considering major sustainability issues related to flood mitigation, environmental, social, economic, policy related and institutional aspects [21]. In view of the above aspects, we have developed a decision support framework (DSF) for sustainability assessment of flood mitigation projects with two major focuses: 1) sustained flood risk reduction by the project and 2) enhanced sustainable development of the floodplain. The framework consists of five stages, defined as per the project life cycle. Details of the framework and methodological procedures have been described in another article earlier published by the authors [18]. This section briefly describes the stepwise process of sustainability assessment using this framework. The application of the framework to a case study project illustrated in the later part of this paper will further clarify the process.

\subsection{Stage 1: Contextualizing the project}

At this stage, we need to contextualize the flood mitigation projects within the floodplain and establish their linkage to regional development programs. Based on the project context, a set of sustainability assessment criteria and indicators should be defined with classified target values in the form of lowest to highest limits and a scoring system. The selected indicators should be used for determining the sustainability index (SI) in the next stages of sustainability assessment.

\subsection{Stage 2: SA in planning and implementation stage}

The second stage of the sustainability assessment needs to be conducted during planning, construction/ implementation, and commissioning of the flood control projects. At the planning stage, various design options will be assessed with the selected sustainability indicators using multi-criteria analysis (MCA) techniques. The SA procedure involves three major steps: (i) determining the relevant applicable indicators and alternative design options, (ii) assigning weightings to these indicators and scoring the indicators for each alternative, and (iii) determining the 'sustainability index' for each alternative using a weighted sum method, thus ranking the alternative design options. The sustainability index $\left(\mathrm{SI}_{\mathrm{i}}\right)$ of an alternative $\mathrm{L}_{\mathrm{i}}$ can be calculated using the following formula (eqn (1)) (adapted from [14], [22].

$$
\mathrm{SI}_{\mathrm{i}}=\sum_{1}^{n} l_{i j} W_{j}(\text { for } \mathrm{i}=1,2,3 \ldots . \mathrm{m} ; \mathrm{j}=1,2,3 \ldots \ldots \mathrm{n})
$$

The design option with the highest SI score will be selected as the most suitable design for implementation.

The same sustainability indicators used for determining the SI should be used for monitoring the construction of the project, and the execution of environmental and social 
management plan. A post-implementation review should be carried out as well. The final set of sustainability indicators will be used for a further SA in the project operation phase.

\subsection{Stage 3: SA during flood event}

Sustainability assessment should be conducted during a flood event to evaluate the performance of the project with respect to the sustainability indicators and the SI, mainly to assess flood risk reduction by the project and performance of the mitigation measures undertaken to minimize negative environmental and social impacts. This assessment will provide a comparative statement of the project's performance and recommendations for improvement.

\subsection{Stage 4: SA at periodic intervals}

Irrespective of flood events, an SA can be carried out at regular intervals, usually every five or ten years in compliance with the country's planning cycle, in order to update information on the changes to land use and economic activities, potential flood risk, and creation of new risks in the project area. The periodic SA will produce a comparative statement of the project's performance as well as, if necessary, revised objectives of the project and targets for sustainability indicators according to upgraded regional development plans and predictable future scenarios.

\subsection{Stage 5: SA at the stage of modification/ changing to a new project}

In the case of modification/ upgrading of the flood mitigation project, the SA process can again start from Stage 2 and continue to 4 . Whereas, if the existing project is transformed into a new project for serving multiple purposes (e.g. transforming a levee project to a levee-cum-road project), the key contexts of SA will change and therefore as it is considering a new project the SA should start from Stage 1 and continue through Stage 4 .

\section{CASE STUDY: DALE STREET FLOOD MITIGATION PROJECT, AUSTRALIA}

A flood mitigation project named the "Dale Street flood mitigation project" in Moreton Bay Regional Council (MBRC), Queensland, Australia was taken as a case study for implementing the sustainability assessment framework (Fig. 1). This project was recently implemented by the council in 2014-2016 periods. The residences and adjoining areas along Dale Street are located within the Burpengary Creek floodplain and are subject to frequent flooding. In recent years, the area was affected by minor to moderate flood events (20\%-5\% AEP) almost every year, with major floods (2\%-1\% AEP) in 2009, 2011 and 2015. Flash flooding with high water depth and velocity typically occurs in the area, residents receive relatively short notice of flood warnings, with the time ranging from 2 to 4 hours, and flood inundation lasts for 4 to 15 hours, isolating the residences for up to 17 hours because of cutting access to the road and properties. The project area covers about $87500 \mathrm{~m}^{2}$ (potentially affected by $100 \mathrm{yr}$ (1\% AEP) flood), where 62 residential properties were located before implementation of the project. Of the 62 properties, 38 properties were subject to above floor flooding. With the aim of reducing the flood damage to properties, roads and other utility services, and the cost and inconvenience of residents' evacuation during flood, the Moreton Bay Regional Council took on the flood mitigation project in 2014 with partial financial support from the Queensland government and the Australian federal government [23]. 
The Dale Street flood mitigation project includes construction of a levee about $740 \mathrm{~m}$ long with floodplain excavation, and acquisition and demolition of 13 flood-prone properties along Dale Street to enable levee construction, and partial acquisition of one property on O'Brien Road for the same purpose. The levee was designed as a mainly earthen structure with $175 \mathrm{~m}$ of concrete wall on the southwestern end. The levee was designed to prevent a $20 \mathrm{yr}$ ARI (5\% AEP) flood with an additional $600 \mathrm{~mm}$ freeboard (that can prevent a $50 \mathrm{yr}$ ARI ( $2 \%$ AEP) flood), and with a maximum height of $2.4 \mathrm{~m}$ above the natural ground. Drainage from the local catchment was channelled through two detention basins and two uni-directional culverts. The levee has been constructed utilizing the soil excavated from the adjacent compensatory cut area in the floodplain. A 50 year life was considered for calculating the cost and benefit of the project. The general layout plan of the project is shown in Fig. 1 [23]. The flood modelling results show that, within the $100 \mathrm{yr}$ ARI flood prone area, the levee project would eliminate flooding in most of the properties to be affected by 20 yr ARI flood events, and only 5-11 properties will remain vulnerable to flooding by a $50 \mathrm{yr}$ ARI to $100 \mathrm{yr}$ ARI flood event in Burpengary Creek [23]. Information concerning the Dale Street flood mitigation project provided in this section was obtained from Moreton Bay Regional Council.

\section{APPLICATION OF THE SA FRAMEWORK TO THE CASE STUDY PROJECT}

This section presents the application of the sustainability assessment framework to the Dale Street flood mitigation project. Since the construction of the project was completed recently in 2016, we have demonstrated here the implementation of Stages 1 and 2 of the framework with the available information. All the considerations and limitations are also presented here. Application of Stage 2 provides the basic calculation and implementation process, most of which will be repeated in Stages 3 and 4 of the framework.

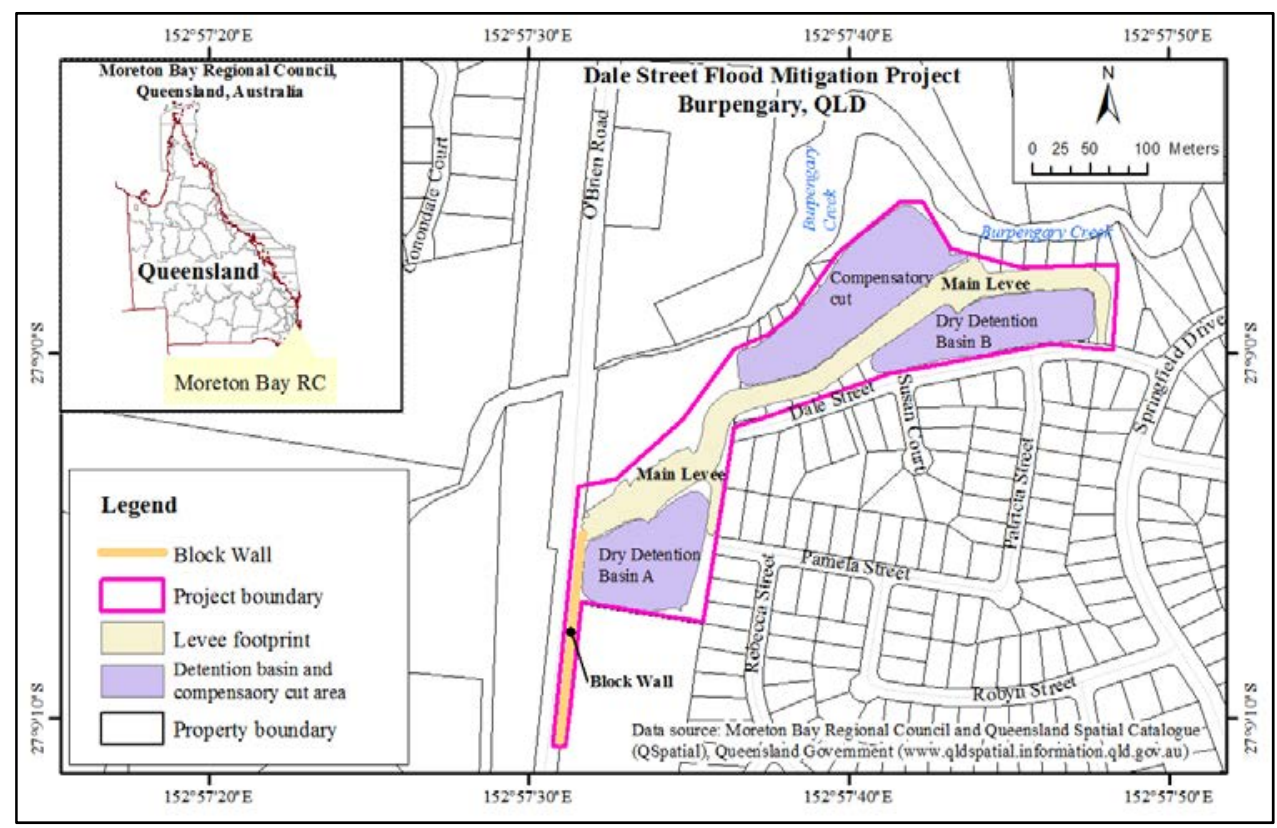

Figure 1: Location and general layout plan of Dale Street flood mitigation project. 


\subsection{Stage 1: Contextualizing the Dale Street flood mitigation project}

As discussed above, the Dale Street flood mitigation project was primarily aimed to protect the properties in the flood prone area, provide safety and convenience to residents, and reduce the damage and maintenance cost of roads and other utility services. After completion of the project, the area will also be used as park land, as an extension to the existing park. We have contextualized the project in various aspects. In term of flood risk reduction, the project will reduce flood damage to residential properties and roads within the $100 \mathrm{yr}$ ARI flood affected area [23]. Since the project is in residential area, the main economic issues are related to resettlement cost, the project life cycle cost, economic viability, funding allocation, and cost for operation and maintenance of the levee and associated structures. The benefit-cost ratio of the project was estimated as 2.1. Most of the cost $(>50 \%)$ was required for property acquisition and demolition. MBRC has provided more than $50 \%$ of the total project cost [23]. Located in a small part of the Burpengary Creek catchment, there is no significant environmental issue; however, typical environmental concerns related to flood mitigation projects prevail in the project areas. These are: changing the natural floodplain, creating a landscape, and diversion of flood flows. Social issues in the project area are mostly related to the safety of residents, their resettlement /displacement from the levee site, community acceptance of the project, and property development in the area. Regarding policy and institutional aspects, the MBRC Council has a separate division for planning, implementation, and maintenance of flood mitigation projects along with other drainage and water management projects. Like other councils in Australia, MBRC has a planning scheme which guides all the development in the council's jurisdiction. Community participation was ensured in the project through consultation for developing the levee design and property relocation issues.

In addition, the relevance of this project to local and state policies and its significance for the sustainable development of the region was determined as well. Also, the objective and impacts of this project can be linked to Australia's sustainable development vision and the measuring indicators (i.e. social and human capital (security, community engagement, governance), natural capital (land, ecosystems, water), and economic capital (housing, infrastructure) [24].

Based on the contexts of the project, as a major output of this stage, the sustainability criteria and indicators for the project have been selected. While selecting the sustainability indicators, we had to consider some basic criteria such as data availability, the potential for long term monitoring, the institutional capacity for data collection, expert judgment, and linkage to sustainable development indicators of the region and the country. All the relevant literature, recent policies, flood study reports, planning, and design documents of the Dale Street project were reviewed for determining the data availability of significant issues to the project and developing a preliminary list of 60 sustainability indicators. Then, experts within Moreton Bay Regional Council and other research agencies were consulted to select the sustainability indicators. They did this on the basis of considering those which are very important to the project and also practically viable for monitoring by the institutions throughout the project life cycle. Finally, 25 sustainability indicators were selected, and categorized under six criteria and two sustainability objectives, as shown in Table 1. The achievable target values (both minimum and maximum) of each indicator were also defined at this stage so that the impact of the flood mitigation project on the indicators could be compared quantitatively or qualitatively. The range of the target values for each indicator was sub-categorized into one to five classes: highly positive, positive, neutral, negative, and highly negative impact. A score of 1 to 5 
was assigned to each impact class. The scores were used to determine the sustainability index in the sustainability assessment of the project in different stages of its life cycle. The SA for Stage 2 is shown in the next section.

Table 1: Sustainability criteria and indicators for Dale Street flood mitigation project.

\begin{tabular}{|c|c|c|}
\hline S1. & Sustainability criteria and indicators & Measuring parameters \\
\hline \multicolumn{3}{|c|}{ Objective 1: Sustainable flood risk reduction } \\
\hline \multicolumn{3}{|c|}{ Criteria-A. Flooding characteristics change } \\
\hline $\mathrm{A} 1$ & Design Flood Level & ARI (e.g. 1:50, 1:100) \\
\hline A2 & Change of flood level outside the project area in future & Increase (\% of flooded area) \\
\hline A3 & Create new type of flooding in the future & Likelihood \\
\hline \multicolumn{3}{|c|}{ Criteria-B. Flood damage reduction } \\
\hline B1 & Reduction of residential property damage & $\%$ of expected damage \\
\hline $\mathrm{B} 2$ & Reduction of damage to roads & $\%$ of expected damage \\
\hline \multicolumn{3}{|c|}{ Objective 2: Contribution to sustainable development of the floodplain } \\
\hline \multicolumn{3}{|c|}{ Criteria-C. Environmental improvement (in the project area) } \\
\hline $\mathrm{C} 1$ & $\begin{array}{l}\text { Extent of land used for the levee construction, concrete } \\
\text { wall and detention basin }\end{array}$ & $\%$ of total project area \\
\hline $\mathrm{C} 2$ & $\begin{array}{l}\text { Use of natural landform to manage flooding in the } \\
\text { project area }\end{array}$ & $\%$ of total project area \\
\hline $\mathrm{C} 3$ & Loss of floodplain habitat (aquatic and terrestrial) & $\%$ of floodplain in the project area \\
\hline $\mathrm{C} 4$ & $\begin{array}{l}\text { Creation of new landscape features other than the levee } \\
\text { (e.g. park \& walkway) }\end{array}$ & $\%$ of total project area \\
\hline $\mathrm{C} 5$ & Diversion of natural water flow from the flood channel & $\begin{array}{l}\% \text { of existing total flood flow at } \\
\text { Design Flood }\end{array}$ \\
\hline \multicolumn{3}{|c|}{ Criteria-D. Social affairs (in the project area) } \\
\hline D1 & Safety of life & $\begin{array}{l}\text { Likelihood of existence of death threat } \\
\text { to people due to flood }\end{array}$ \\
\hline D2 & Displacement of people due to levee project & $\%$ of affected properties or households \\
\hline D3 & $\begin{array}{l}\text { Highly vulnerable population (children, the elderly and } \\
\text { the autistic) }\end{array}$ & $\%$ of total population \\
\hline D4 & Community preparedness for floods & $\begin{array}{l}\% \text { of households taking preventive } \\
\text { measures }\end{array}$ \\
\hline D5 & Acceptance by the stakeholders & $\%$ of affected property owners \\
\hline D6 & Population growth & $\%$ per year \\
\hline D7 & Change of property development areas & $\%$ of area change per year \\
\hline \multicolumn{3}{|c|}{ Criteria-E. Economy (in the project area) } \\
\hline E1 & Financial viability (over project life) & Benefit-cost ratio \\
\hline E2 & Share of funds from local government & $\%$ of total project life cycle cost \\
\hline E3 & $\begin{array}{l}\text { Contribution of local community or the council to } \\
\text { O\&M cost }\end{array}$ & $\%$ of total O\&M cost \\
\hline \multicolumn{3}{|c|}{ Criteria-F. Policy and institutions (in the region) } \\
\hline F1 & $\begin{array}{l}\text { Existence of updated regional and local flood } \\
\text { mitigation plan and planning scheme }\end{array}$ & Status of plans and policies \\
\hline $\mathrm{F} 2$ & Ensured community participation & Level of participation \\
\hline F3 & Engagement of local professionals & $\%$ of total staff in the project \\
\hline F4 & Separate institutional unit for the project & Status of institutional unit \\
\hline F5 & Engagement of local contractors & Level of engagement \\
\hline
\end{tabular}


4.2 Stage 2: SA in the planning and implementation phase

In the planning and design stage, several preliminary design alternatives were considered. In this study, we considered the two most viable alternatives for assessing sustainability. Alternative A, for 5 yr ARI (20\% AEP) flood protection, included constructing a 540m levee bank along Dale Street and the eastern edge of 46 O'Brien Road, floodplain excavation and acquisition of 10 properties along Dale Street. Alternative B included a $790 \mathrm{~m}$ levee bank in the same location, floodplain excavation, and acquisition of 13 properties along Dale Street for 20 yr ARI (5\% AEP) flood protection. Both alternatives were investigated by Moreton Bay Regional Council in their preliminary flood mitigation investigation work undertaken in 2013. The 25 indicators listed in Table 1 were used for sustainability assessment of the alternatives using a multi-criteria analysis (MCA) technique. A total of 100 weight was distributed to the indicators based on their importance to the project. The values of the sustainability indicators for the impact of the alternatives were determined from the flood modeling studies and environmental and socioeconomic assessments. Then, for each alternative, the score for each indicator was assigned, based on which impact class the value of indicator fell into. The score of each indicator was then multiplied by the weight of the indicator. For instance, weighted scores for the indicators on flood characteristics (A1 and A2) were determined for Alternative B based on the value of indicators obtained by the flood modeling study of the project area (Table 2). The weights of the indicators were defined by the experts consulted for this research. The score for each indicator was based on the impact class defined in Table 3, where a high positive impact means a high contribution towards the sustainability of the project. Similarly, weighted scores for all 25 indicators were calculated for Alternatives A and B. Finally, a sustainability index (SI), i.e. the sum of the weighted scores, was calculated as 311 and 431 for Alternative A and Alternative B respectively (Fig. 2). The high difference in SI values between these alternatives was due to the flood prevention capacity of these two options. Alternative A was designed for $5 \mathrm{yr}$ ARI flood protection, whereas Alternative B was designed for $20 \mathrm{yr}$ ARI flooding. Although Alternative B was designed to cover a larger

Table 2: Example of scores for the indicators for Alternative B in the planning phase.

\begin{tabular}{llcccc}
\hline Sustainability indicators (units) & $\begin{array}{c}\text { Value for } \\
\text { Alt. B }\end{array}$ & Score* & Weight & $\begin{array}{c}\text { Weighted } \\
\text { score }\end{array}$ \\
\hline A1 & $\begin{array}{l}\text { Design Flood Level (ARI) } \\
\text { Change of flood level outside the project }\end{array}$ & $20 \mathrm{yr}$ & 3 & 15 & 45 \\
A2 $\begin{array}{l}\text { area in future (\% increase of flooded } \\
\text { area) }\end{array}$ & $0 \%$ & 5 & 5 & 25 \\
\hline *
\end{tabular}

*scores taken from Table 3.

Table 3: Example of impact class and scores for various values of the indicators.

\begin{tabular}{cccccc}
\hline \multirow{2}{*}{$\begin{array}{c}\text { Sustainability } \\
\text { indicators }\end{array}$} & \multicolumn{5}{c}{ Impact class and scores for different values of the indicator } \\
\cline { 2 - 6 } & $\begin{array}{c}\text { Highly negative } \\
\text { impact (or very low } \\
\text { positive impact) }(1)\end{array}$ & $\begin{array}{c}\text { Negative impact } \\
\text { (or low positive } \\
\text { impact) }(2)\end{array}$ & $\begin{array}{c}\text { Neutral } \\
(3)\end{array}$ & $\begin{array}{c}\text { Positive } \\
\text { impact (4) }\end{array}$ & $\begin{array}{c}\text { Highly } \\
\text { positive } \\
\text { impact (5) }\end{array}$ \\
\hline A1 & $5 \mathrm{yr}$ & $10 \mathrm{yr}$ & $20 \mathrm{yr}$ & $50 \mathrm{yr}$ & $\begin{array}{c}100 \mathrm{yr} \text { and } \\
\text { over }\end{array}$ \\
A2 & $>15 \%$ & $10-15 \%$ & $5-10 \%$ & $<5 \%$ & $0 \%$ \\
\hline
\end{tabular}




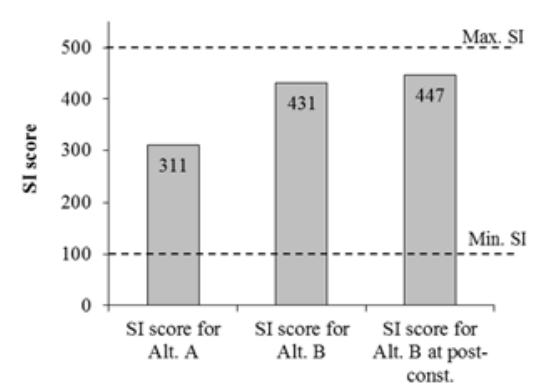

(a)

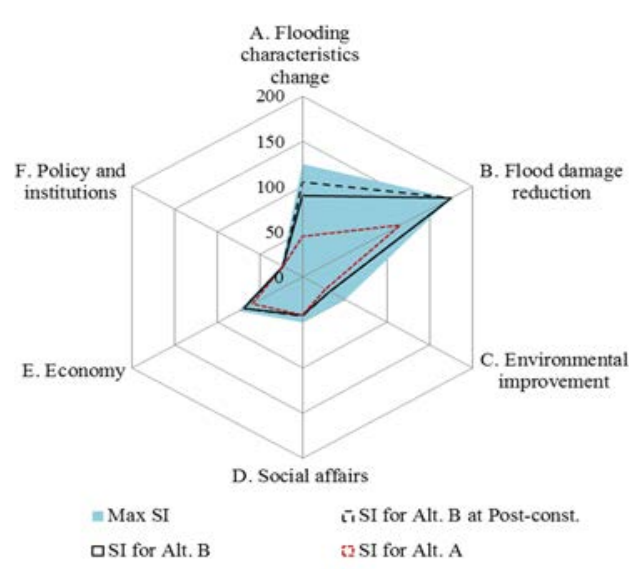

(b)

Figure 2: SI score for the project alternatives and project commissioning stage. (a) SI for alternatives and at postconstruction phase; (b) Status of sustainability criteria for the alternatives and at post-construction phase.

area with more extensive structures than Alternative A, the negative impacts were not significantly greater than that of Alternative A. As mentioned earlier, the project has already been implemented with some improvement of the Alternative B design. This sustainability assessment reinforced the suitability of the Alternative B.

Further, the sustainability assessment of the project at the commissioning (postconstruction) stage was carried out. Alternative B was implemented with some modification of the levee design (e.g. reducing length, increasing levee height with $600 \mathrm{~mm}$ freeboard, widening detention basin area, extending park area, etc.), which would be able to prevent up to a $50 \mathrm{yr}$ ARI ( $2 \%$ AEP) flood and provide greater benefit to the community. The SI for the project at commissioning stage was increased to 447 (Fig. 2). This increase of SI score from the planning stage to final implementation was mainly due to change of flood characteristics and reduction of potential flood risk. Other sustainability indicators were not much influenced by the final levee design. Overall, the results suggested that the project was implemented with further improvement towards sustainability.

\subsection{Stages 3 to 5 of the SA framework}

The remaining stages of the SA framework (Stages 3 to 5) can be further implemented for the project throughout the project life. The process would be similar to the planning and implementation stage, with some variation of sustainability indicators and values appropriate at the time of application in future. Necessary adjustment of the indicators and scores would be required through consultation with experts and stakeholders.

\section{DISCUSSION}

This study illustrated the application of a sustainability assessment framework for a flood mitigation project. This conceptual sustainability assessment framework developed by the authors was based on generalized and broader perspectives for flood mitigation projects and floodplains. Application of the SA framework to the case study flood mitigation project revealed the real value of the assessment and its suitability for decision making. Although 
the SA framework includes all stages of the project lifecycle, we could only perform the assessment up to Stage 2 (project planning and implementation) due to the recent implementation of the project. The results for this case study project showed that there was improvement toward sustainability from the preliminary planning stage (defining suitable alternatives) through the final implementation of the project. This finding can confirm the applicability of the framework to indicate whether the selected alternative would be sustainable or not, a major concern of the SA process [16], [17]. The SA framework aims to improve the conventional assessment and decision making process for flood mitigation projects by considering the project performance throughout project life and influence on the sustainable floodplain development, rather than focusing only on construction and maintenance of flood mitigation structures [16].

The computation process of the SA framework followed methods easily applicable by the policy maker. The main challenges for implementing the SA framework remain with the selection of suitable sustainability criteria and indicators that support the purposes of the decision makers and determining the values of indicators for the assessment. The values of some indicators need to be determined by a complex modeling exercise carried out by detailed investigations, for example, a flood modeling study. Record collection and database maintenance for future reference would be crucial for successfully generating the outputs of the sustainability assessment and consequently for its usefulness to the decision makers.

The overall sustainability index (SI) could be sensitive to the weight of the sustainability indicators as well as to the uncertainty of the values of the indicators [11], [25]. The weights of indicators are dependent on the policy makers and stakeholders as well as on the context of the project [26], which could lead to various combinations of outputs. This uncertainty about the indicators' value would add further complexity, but is inevitable as all future forecasts always contain several assumptions and face uncertainty [27]. The current research can be extended to perform sensitivity analysis and uncertainty analysis and determine their impact on the SI. Sustainability assessment of several possible scenarios of the project could be further explored to visualize the possible outcomes of the project under various conditions, which is especially required for large flood mitigation projects with phase-wise implementation involving a large group of stakeholders.

Overall, the application of the proposed SA framework reflects the possibilities for decision making considering the sustainable outputs of individual projects as well as linking these to the sustainable development of the region. It is worth mentioning that no methodological framework for this type of multi-criteria based analysis can include all the complex dimensions and relationships of the environmental and socio-economic aspects and all possible impacts [28]. The proposed SA framework is not necessarily the best one, but rather a credible one that can be readily used by planners and decision makers.

\section{CONCLUSIONS}

Achieving sustainability of flood mitigation projects and sustainable development in the floodplains has been a great concern to the flood managers for a long time. This study has shown an application of a proposed sustainability assessment framework for flood mitigation project in case of a flood levee project. Findings of the study suggest that sustainability assessment of the flood mitigation project using the SA framework will help to determine the best suitable alternative and continuous improvement of the project outcome as well as achieving sustainable development in the floodplain. The SI scores and indicators determined in the assessment gives an indication of how well the project is expected to perform, which is vital for decision making. The SA framework provides a 
pathway for continuous assessment of the project throughout its life cycle. Instead of a onetime decision-making system in every stage of the project, the proposed SA framework would help long-term project management in terms of improving capture of the sustainability issues of the project by tracking the status of the sustainability indicators as well as integrating the future needs. This framework can be further improved by creating a user-friendly automated process such as GIS-based computer software. Moreover, the application of the SA framework can be examined for all types of structural and nonstructural flood mitigation projects as well as for other similar projects like road infrastructure.

\section{REFERENCES}

[1] Wamsler, C., Managing urban risk: perceptions of housing and planning as a tool for reducing disaster risk. Global Built Environment Review, 4, pp. 11-28, 2004.

[2] Schipper, L. \& Pelling, M., Disaster risk, climate change and international development: scope for, and challenges to, integration. Disasters, 30, pp. 19-38, 2006.

[3] Environment Agency, Flood and Coastal Erosion Risk Management appraisal guidance, Environment Agency: UK, 2010.

[4] DNRM, Guidelines for the construction or modification of category 2 and 3 levees. Department of Natural Resources and Mines (DNRM), Queensland Government: Queensland, 2014.

[5] Shah, M.A.R., Rahman, A. \& Chowdhury, S.H., Challenges for achieving sustainable flood risk management. Journal of Flood Risk Management, 2015. DOI: 10.1111/jfr3.12211.

[6] Sadler, B., On evaluating the success of EIA and SEA. Assessing impact: Handbook of EIA and SEA follow-up, eds A. Morrison-Saunders \& J. Arts, Earthscan: UK and USA, pp. 248-285, 2004.

[7] Dalal-Clayton, B. \& Sadler, B., Sustainability appraisal: a sourcebook and reference guide to international experience, Routledge: London and New York, 2014.

[8] Nelson, P., Building capacity in SEA in sub-Saharan Africa. Paper presented at the 23rd Annual Meeting of the International Association for Impact Assessment (IAIA'03), Marrakech, Morocco, 2003.

[9] Knippenberg, L., Haarmann, W., Hermans, F., Beckers, T., Dagevos, J. \& Overeem, I., Developing tools for the assessment of sustainable development in the province of Brabant, the Netherlands. Sustainability indicators: a scientific assessment, eds T. Hák, B. Moldan \& A.L. Dahl, Island Press: Washington, pp. 309-328, 2007.

[10] ODPM, Sustainability Appraisal of Regional Spatial Strategies and Local Development Documents: Guidance for Regional Planning Bodies and Local Planning Authorities, United Kingdom Office of the Deputy Prime Minister: UK, 2005.

[11] Edjossan-Sossou, A.M., Deck, O., Al Heib, M. \& Verdel, T., A decision-support methodology for assessing the sustainability of natural risk management strategies in urban areas. Natural Hazards and Earth System Sciences, 14, pp. 3207-3230, 2014.

[12] Uehara, T., Niu, J., Chen, X., Ota, T. \& Nakagami, K.I., A sustainability assessment framework for regional-scale Integrated Coastal Zone Management (ICZM) incorporating Inclusive Wealth, Satoumi, and ecosystem services science. Sustainability Science, 11(5), pp. 801-812, 2016. 
[13] Varey, W., Integrated approaches to sustainability assessment: An alignment of ends and means. Presented at the 24th Annual Meeting and Conference of the International Association for Impact Assessment (IAIA), Vancouver, Canada, 2004.

[14] Ugwu, O.O., Kumaraswamy, M.M., Wong, A. \& Ng, S.T., Sustainability appraisal in infrastructure projects (SUSAIP): Part 1. Development of indicators and computational methods. Automation in construction, 15, pp. 239-251, 2006.

[15] Kumar, V., Rouquette, J. \& Lerner, D., Integrated modelling for Sustainability Appraisal for Urban River Corridor (re)-development. Procedia Environmental Sciences, 13, pp. 687-697, 2012.

[16] DEFRA, Sustainable Flood and Coastal Erosion Risk Management (Part -1), Department for Environment, Food and Rural Affairs (DEFRA): UK, 2007a.

[17] DEFRA, Sustainable Flood and Coastal Erosion Risk Management (Part -2), Department for Environment, Food and Rural Affairs (DEFRA): UK, 2007b.

[18] Shah, M.A.R., Rahman, A. \& Chowdhury, S.H., Life Cycle Based Decision Support Framework for Assessing Sustainability of Structural Flood Mitigation Projects. Presented at the 56th Floodplain Management Association Conference, Nowra, New South Wales, Australia, 2016.

[19] DLPE, Environmental assessment report and recommendations, Alice SpringsEastside levee proposal, Department of Lands, Planning and Environment (DLPE), Northern Territory Government: Australia, 2000.

[20] IBWC, Environmental Assessment for Flood Control Improvements Lateral A/Retamal Dike Levee System, United States Section, International Boundary and Water Commission (IBWC): Texas, 2007.

[21] Carter, J.G., White, I. \& Richards, J., Sustainability appraisal and flood risk management. Environmental Impact Assessment Review, 29, pp. 7-14, 2009.

[22] Fishburn, P.C., Additive Utilities with Incomplete Product Set: Applications to Priorities and sharings, Operations Research Society of America (ORSA): Baltimore, MD, USA, 1967.

[23] MBRC, Moreton Bay Regional Council (MBRC), Queensland, Australia, 2015.

[24] Commonwealth of Australia, Sustainable Australia - Sustainable Communities: A Sustainable Population Strategy for Australia, Commonwealth of Australia, 2011.

[25] Olbrich, R., Quaas, M.F. \& Baumgärtner, S., Sustainable use of ecosystem services under multiple risks-a survey of commercial cattle farmers in semi-arid rangelands in Namibia. Working Paper Series in Economics, (137), Leuphana University of Lüneburg: Germany, 2009.

[26] Mitchell, G., Problems and fundamentals of sustainable development indicators. Sustainable Development, 4(1), pp. 1-11, 1996.

[27] Zhu, Z., Bai, H., Xu, H. \& Zhu, T., An inquiry into the potential of scenario analysis for dealing with uncertainty in strategic environmental assessment in China. Environmental impact assessment review, 31(6), pp. 538-548, 2011.

[28] Helming, K., et al., Ex ante impact assessment of policies affecting land use, part B: application of the analytical framework. Ecology and Society, 16(1), 2011. 